\title{
Neue Ordnungsökonomik
}

\author{
Hrsg. v. Joachim Zweynert, Stefan Kolev u. Nils Goldschmidt
}

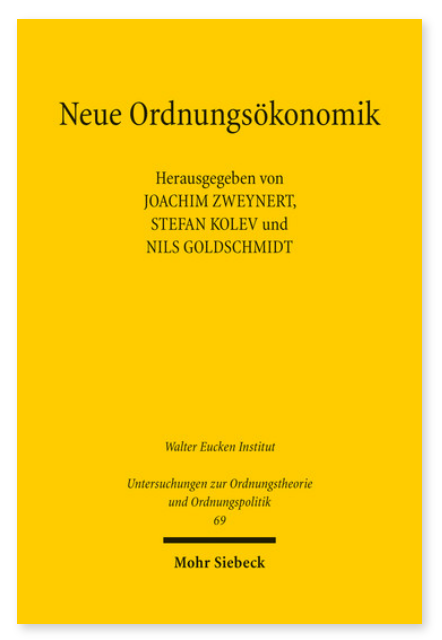

2016. VIII, 252 Seiten. UOrd 69

ISBN 978-3-16-152995-5 eBook PDF $69,00 €$

ISBN 978-3-16-152994-8

fadengeheftete Broschur 69,00€
Die Wogen des neuerlichen oder auch »dritten« Methodenstreits haben sich geglättet, der Streit über Sinn und Nutzen der Ordnungsökonomik scheint beigelegt und die Ökonomen-Zunft zum Tagesgeschäft zurückgekehrt zu sein. Von Ruhe kann jedoch keine Rede sein. Vielmehr hat sich der Schwerpunkt der Debatte verlagert. Ging es zunächst um 'große' und grundsätzliche Fragen, geht es nun um konkrete und praktikable Vorschläge, die dazu beitragen können, jene methodischen Defizite zu überwinden, die der Volkswirtschaftslehre die Erkenntnis der Wirtschaftswirklichkeit erschweren. Wenn es ein einfaches Zurück zur alten Ordnungsökonomik nicht geben kann, wie könnte dann eine Neue Ordnungsökonomik aussehen, die auch explizit an internationale Diskurse anschließt, sich aber gleichzeitig in der Tradition Euckens, Böhms und Röpkes sieht? Dies ist die Frage, die sich die Autoren dieses Bandes gestellt haben.

\section{Inhaltsübersicht}

Joachim Zweynert/Stefan Kolev/Nils Goldschmidt: Neue Ordnungsökonomik. Zur Aktualität eines kontextualen Forschungsprogramms - Florian Möslein: Regelsetzung und Ordnungsökonomik - Péter Cserne: Models of Human Behaviour in Economics, Policy and the Law - Lars Feld/Ekkehard Köhler: Ist die Ordnungsökonomik zukunftsfähig? - Inga Fuchs-Goldschmidt/Nils Goldschmidt: Wiesel oder Hermelin? Strukturelle Gerechtigkeit als Fundament einer modernen Sozialen Marktwirtschaft - Lars Feld/Ekkehard Köhler: Eine Replik auf Fuchs-Goldschmidt und Goldschmidt - Carsten Herrmann-Pillath: Hayek 2.0: Grundlinien einer naturalistischen Theorie wirtschaftlicher Ordnungen - Jan Schnellenbach: Politisch-ökonomische Implikationen der Verhaltensökonomik: eine kritische Bestandsaufnahme - Gerhard Wegner/Temime Mechergui: Zur politischen Ökonomie kolonialer und neopatrimonialer Regime am Beispiel Tunesiens - Michael Wohlgemuth/Stefan Kolev: Evolutorische Public Choice und Neue Ordnungsökonomik - Gerald Braunberger: Ordnungsökonomik ist nicht genug. Unsystematische Beobachtungen eines Wirtschaftsjournalisten

Joachim Zweynert Geboren 1970; Studium der Volkswirtschaftslehre und Politikwissenschaft; 2002 Promotion; 2006 Habilitation; seit 2013 Professur für Internationale Politische Ökonomie an der Universität Witten/Herdecke; Research Fellow am Hamburgischen WeltWirtschaftsInstitut (HWWI); Gründungsdirektor des Wittener Instituts für institutionellen Wandel (WIWA).

Stefan Kolev Geboren 1981; Studium der Betriebswirtschaftslehre und Volkswirtschaftslehre; 2011 Promotion; seit 2012 Professur für Wirtschaftspolitik an der Westsächsischen Hochschule Zwickau; stellv. Vorsitzender des Wilhelm-RöpkeInstituts, Erfurt; Research Fellow am Hamburgischen WeltWirtschaftsInstitut (HWWI); Research Fellow am Center for the History of Political Economy at Duke University.

Nils Goldschmidt ist Professor für Kontextuale Ökonomik und ökonomische Bildung an der Universität Siegen.

Jetzt bestellen:

https://mohrsiebeck.com/buch/neue-ordnungsoekonomik-9783161529955?no_cache=1

order@mohrsiebeck.com

Telefon: +49 (0)7071-923-17

Telefax: $+49(0) 7071-51104$ 